\title{
The Adoption of Big Data Analytics Among Manufacturing Small and Medium Enterprises During Covid-19 Crisis in Malaysia
}

\author{
Chun-Hong Loh ${ }^{1 *}$, Ai-Ping Teoh ${ }^{2}$
}

\author{
${ }^{1}$ Cipli Hardware Sdn Bhd, TBP314 Lorong Kubor Off, 12200 Butterworth Penang, Malaysia \\ ${ }^{2}$ Graduate School of Business, Universiti Sains Malaysia, 11700 Gelugor Penang, Malaysia \\ *Corresponding author.Email: dariusloh@hotmail.com
}

\begin{abstract}
Global epidemic Coronavirus Disease 2019 (COVID-19) has a significant impact on the global economy. The Big Data Analytics (BDA), which helps businesses to obtain useful insights, is seen as a new strategic weapon in industry particularly during this challenging time. This study investigated the influence of technological factors on BDA adoption among Malaysian manufacturing Small and Medium Enterprises (SMEs). The data was collected from 185 manufacturing SMEs in Malaysia and analysed using SmartPLS version 3.3.2. This study uncovers significant technological factors that drive BDA adoption and highlight the role of technological resource competency as a mediator in this model. The findings contribute to the Malaysian SMEs to strategize BDA adoption in today's dynamic business environment, and can be a reference to ASEAN developing nations as well.
\end{abstract}

Keywords: Big Data Analytics, Small and Medium Enterprises, Technological Resource Competency, Malaysia

\section{INTRODUCTION}

The 2019 - 2020 coronavirus pandemic is continuing to be the global epidemic of Coronavirus Disease 2019 (COVID19). Covid-19 is affecting 176 countries and territories around the world. The number of cases has risen to over 735,000 and 35,000 as of $30^{\text {th }}$ March 2020 and it will still continue to grow [1]. The COVID-19 outbreaks in many countries such as Europe, Korea, Japan, the United States, and elsewhere, as the authorities are implementing increasingly restrictive measure to contain the virus. Most of the countries to prevent the outbreak of the virus have the choice to lock down their cities, states, or the whole countries. This has had a significant impact on the global economy. Since $25^{\text {th }}$ January 2020, the COVID-19 was confirmed spreading to Malaysia. Within two months, there were more than 2908 confirmed cases which become the highest of known infection in Southeast Asia [2]. Malaysian government has decided to implement a "Movement Control Order" (MCO) to curb the further growth of positive cases in the country through social distancing. This announcement brings out the issue of the sustainability of Malaysian SMEs during COVID-19 crisis and the impact from MCO. SMEs are the backbone of the economy of Malaysia, in which $98.5 \%$ of business establishments are SMEs (DOSM, 2019). The current survey done by the SME association of Malaysia found that more than $51.2 \%$ of the SMEs is expected to incur over RM500,000 losses within six months [3].
Big data is not an attempt at "once and done". Big data's aim is to help the SMEs see the next transformative breakthrough around the corner. Continuous data collection to assess the trends is essential for predictive analysis. Data collection must be built into the organization's daily processes to ensure its accuracy and timeliness. One of the key features of big data is 'Velocity'. In this sense, velocity is the needs of organizations to continuously store, integrate, and analyse new data in real time. The SMEs would have to develop a data management roadmap after clearly identifying the key insights required to run a business today as well as in the future, and the data is needed to produce those insights.

Cashflow is the biggest challenge for SMEs. The majority of SMEs are tight in cashflow. Due to MCO, it is expected that there will be no cash inflow. However, the SMEs will still have to pay full wage, rental, and some statutory payments. Since the survey data defined that the issues and problems might happen after the MCO, SMEs are projected to urgently implement the plan ahead. One of the best ways is to adopt the Big Data Analytics (BDA). In general, there are various influencing factors that decide BDA adoption [4]. As the technical determinants which may affect BDA adoption in the Malaysian market for SMEs, the influence of relative advantages, complexity, and compatibility should be looked at [5]. The IT infrastructure and human capital are both parts of the organization's technical capital skills [6].

This condition confirms that further studies are being carried out to examine the drivers behind the extremely complex adoption procedure in BDA [7]. Currently, 
researcher have given the BDA considerable attention. However, limited research has examined the important organizational determinants of decision to implement this technology [8]. BDA is focussed on the aspects of technology, organization, and the environment, and has positive impact on the business success [9]. However, theoretical framework has not been established which takes full account of all these prospects for implementing BDA and it is largely uncharted to predict the value of factors influencing the use of BDA [7]. Most studies have been conducted in the developed world on the use of BDA. More analysis needs to be done in the sense of less developed and developing countries [10].

\subsection{Literature Review}

The technological context focuses on the characteristics of the technology which may affect the decision-making process, either positively or negatively, if such a new technology should be implemented [11]. Based on previous studies [11], the three most important features in deciding on implementation of innovation include relative advantage, compatibility, and complexity.

\subsubsection{Relative Advantage}

Relative advantage is described as how a technology can better serve a business than its current implementation. Companies should take into account the benefits of innovation [12]. In the past, the relative value of innovation was found to be positive in relation to adoption [13]. Research has indicated that if a consumer has a perceived advantage or utility of a new technology over an old one, it appears that the consumer will take on it [14]. SMEs are more likely to adopt the latest technology, if it increases business efficiencies [15], and the relative advantage is also important. The following hypothesis is suggested as follow.

$\mathrm{H}_{1}$ : Relative advantage positively affects big data analytics adoption.

\subsubsection{Complexity}

Complexity refers to the extent to which an invention is considered to be very hard to understand and use [12]. The possibility for adoption is hindered by a complex technology. A company cannot trust BDA, because it is fairly new to them [6]. The absence of IT professionals and professional knowledge threatens the technology adoption [16]. A number of studies show that sophistication on IT adoption has a detrimental effect [6]. The large volume of data collected is a key source of uncertainty within BDA. In certain situations, to be valuable knowledge, the data must also be processed [11]. Companies will train or introduce talent to BDA, finance BDA operations, and promote the delivery of BDA through inter-agency functions. Technological complexity can prevent companies from implementing new technological innovations [17]. The following hypothesis is suggested as follow.

$\mathrm{H}_{2}$ : Complexity negatively affects big data analytics adoption.

\subsubsection{Compatibility}

Compatibility refers to the degree to which an invention is considered to be in line with potential adopters' expectations or current practice. It is possible that a corporation adopts a technology consistent with the structure of organization and its purpose. The deciding factor for product adoption is compatibility [16]. For instance, the de-loading of BDA infrastructure capability into BDA infrastructure makes economic sense when using the scalability advantage for low-security applications [13]. When current experiences of information technology entities are compliant with the BDA implementation and suit the existing information infrastructure, the improvements implemented by BDA adoption will be aligned with established practices, and BDA's positive effect is likely to occur and will promote the BDA adoption in a favourable manner. Many studies have found positive and significant impacts of technology assimilation compatibility [6]. The following hypothesis is suggested as follow.

$\mathrm{H}_{3}$ : Compatibility positively affects big data analytics adoption.

\subsubsection{Technological resource competency}

Technological resource competency relates to technology readiness, it blends IT infrastructure and IT capability [5]. In addition to physical technological assets, intangible technical awareness of human capital provides information that needs to be built and successfully incorporates new technological applications [16]. Technological resource competence in technical resources is characterized as the level of specialized BDA knowledge, skills, and related ebusiness applications. If human resources are sufficiently aware of the importance of new technologies in business operations, businesses are more likely to embrace this innovation and increase their willingness to introduce it [16]. Most literature demonstrates the positive relationship between technological resource competency and the organizational context [6]. Thus, the hypothesis is suggested below.

$\mathrm{H}_{4}$ : Technological resource competency positively affects big data analytics adoption.

\subsubsection{The mediating role of technological resource competency}

In addition to direct impacts of technological factor on BDA adoption, technological resource competency is proposed 
and tested to mediate the influence of technological factors on BDA adoption (Figure 1). Organizations require internal knowledge on their financial position, inventory quality, manufacturing cost, and so on. They also need external information on the environment in which they operate customer, competitors, and suppliers, that will help them to get to know and satisfy their clients quickly and efficiently, and thereby achieve enduring competitive advantage. BDA is a widespread innovation, but it needs considerable skills as regards the IT and management which can fundamentally turn strategic planning into operations for any business. Technologies for more transformative progress require major improvements in organizational practices, structures, and policies [18]. In the literature, there is limited research examining the mediating role of technological resource competency. In a study of industry of ceramic title firms, technological resource competency and the commercial success of innovation was tested [19]. By synthesizing similar previous studies regarding the effect of technological factors on BDA adoption, the hypothesis can be suggested as follow.

$\mathrm{H}_{5}$ : Technological resource competency positively mediates the relationship between relative advantage and big data analytics adoption.

$\mathrm{H}_{6}$ : Technological resource competency positively mediates the relationship between complexity and big data analytics adoption.

$\mathrm{H}_{7}$ : Technological resource competency positively mediates the relationship between compatibility and big data analytics adoption

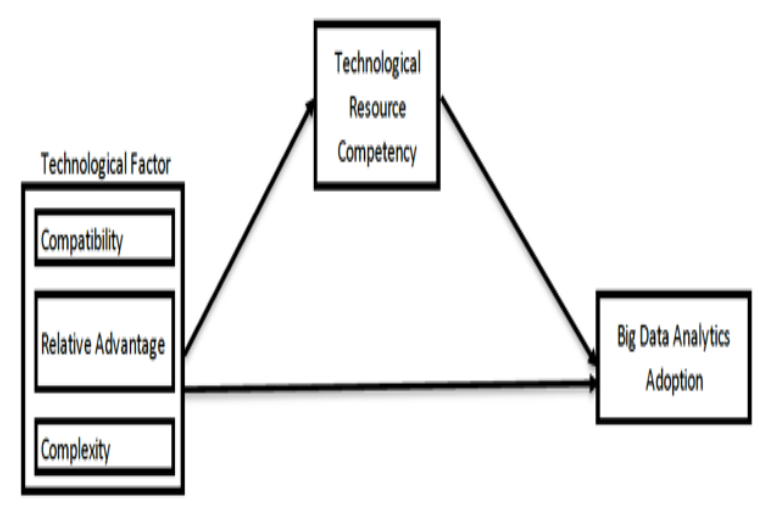

Figure 1 Research model

\section{RESEARCH METHODOLOGY}

The goal of this study is to identify the influence of technological factors such as compatibility, relative advantage, and complexity on BDA adoption, and to test the role of technological resource competency as a mediator in this relationship among Malaysian manufacturing SMEs. A quantitative study was conducted to obtain responses from the targeted respondents.

\section{A. Sample and data collection}

Given the research purpose, we used questionnaires survey and collected 185 usable responses from the manufacturing SMEs in Malaysia.

\section{B. Measures}

Partial Least Square (PLS) methods has been used to analyse the relationship among the main constructs. The measurement model and structural model are tested using Smart-PLS version 3.2.2. PLS-SEM analytics has been chosen, because they can simultaneously evaluate every direction and do not need a big sample size. Further reasons for using PLS-SEM include the non-normal results, new relationships, small samples, and prediction-oriented analysis [20]. The sample size has been tested using software G*Power, since our study PLS model involves 3 predictors of BDA adoption. A minimum sample size of 55 was needed to generate power of 0.80 for our PLS model with a medium effect size of 0.15 [20]. Therefore, our PLS model has accomplished and gained more strength with 185 respondents as the required sample size criterion. The response was measured using seven-point Likert scale.

\section{DATA ANALYSIS AND RESULTS}

\section{A. Demographic Profile}

There were $91.89 \%$ of respondents who adopted BDA. Most of the respondent was from the category of basic metal products industry $(24.71 \%)$. Most of the respondents have been working for more than 11 years in the company and their company is using the IT model in mixed-mode. Majority of the respondent business revenues were more than RM10 million with employees less than 75 .

\section{B. Measurement Model Analysis}

By assessing the validity and reliability, the integrity of the measures has been established. Reliability refers to the quality of the assessment instrument for the constant measurement of a concept, while validity evaluates the quality of the instrument for developing measures in a particular concept [21]. Figure 2 shows that the measuring models of all values are above those suggesting convergent validity with all the structures are above the minimum value of 0.5 . 


\begin{tabular}{|c|c|c|}
\hline Constructs & Items & Loadings \\
\hline $\begin{array}{c}\text { Big Data Analytics } \\
\text { Adoption }\end{array}$ & BDA1 & 0.956 \\
& BDA2 & 0.961 \\
& BDA3 & 0.942 \\
\hline \multirow{4}{*}{ Relative Advantage } & RA1 & 0.916 \\
& RA2 & 0.957 \\
& RA3 & 0.931 \\
& RA4 & 0.932 \\
\hline \multirow{4}{*}{ Compatibility } & CO1 & 0.901 \\
& CO2 & 0.945 \\
& CO3 & 0.952 \\
Complexity & CO4 & 0.928 \\
\hline \multirow{2}{*}{ Technological Resource } & CX1 & 0.890 \\
Competency & CX2 & 0.929 \\
& CX3 & 0.799 \\
\hline
\end{tabular}

Figure 2 Convergent validity of constructs

The measurement analysis of the values of Composite Reliability (CR), Average Variance Extracted (AVE), reliability coefficient (rho A), and Cronbach's Alpha are shown in Figure 3 about the constructs' reliability and validity. The CR values is more than 0.6 for each construct.

\begin{tabular}{|c|c|c|c|c|}
\hline Constructs & AVE & CR & rho_A & $\begin{array}{c}\text { Cronbach's } \\
\text { Alpha }\end{array}$ \\
\hline $\begin{array}{c}\text { Big Data Analytics } \\
\text { Adoption }\end{array}$ & 0.908 & 0.967 & 0.950 & 0.950 \\
\hline Relative Advantage & 0.873 & 0.965 & 0.954 & 0.951 \\
\hline Compatibility & 0.764 & 0.906 & 0.950 & 0.949 \\
\hline Complexity & 0.868 & 0.963 & 0.909 & 0.851 \\
\hline $\begin{array}{c}\text { Technological Resource } \\
\text { Competency }\end{array}$ & 0.841 & 0.941 & 0.910 & 0.906 \\
\hline
\end{tabular}

Figure 3 Constructs' reliability and validity

The heterotrait-monotrait ratio (HTMT) threshold value is less than 0.85 as conservative limit [22]. Figure 4 shows the Heterotrait-Monotrait (HTMT) for all constructs.

\begin{tabular}{|c|c|c|c|c|c|}
\hline & BDA & CO & CX & RA & TRC \\
\hline BDA & & & & & \\
\hline CO & 0.758 & & & & \\
\hline CX & 0.365 & 0.395 & & & \\
\hline RA & 0.840 & 0.801 & 0.386 & & \\
\hline TRC & 0.655 & 0.586 & 0.461 & 0.538 & \\
\hline
\end{tabular}

Figure 4 Heterotrait-Monotrait (HTMT)

\section{Assessment of Structural Model}

A review of the Coefficient of Determination $\left(\mathrm{R}^{2}\right)$, effect size $\left(\mathrm{f}^{2}\right)$, path coefficients $(\beta)$, and predictive relevance $\left(\mathrm{Q}^{2}\right)$ are the measurements of the structural model. To define the collinearity, Variance Inflation Factor (VIF) values were tested. All the constructs had VIF values between 1.276 and 2.603. Upon evaluating the VIF values, the bootstrapping approach was applied with 500 resamples using PLS 3.3.2 to obtain the values of standard path coefficients, t-values, and standard errors to analyse the importance of the relationship between each of the hypotheses [20]. Figure 5 shows the structural model's path analysis as well as the significant relationships between the direct path coefficients.

\begin{tabular}{|l|c|c|c|c|}
\hline \multicolumn{1}{|c|}{ Hypotheses } & $\boldsymbol{\beta}$ & SD & T-statistics & P-values \\
\hline H1:RA-> BDA & 0.545 & 0.093 & $5.913^{* *}$ & 0 \\
\hline H2:CX-> BDA & -0.017 & 0.049 & 0.455 & 0.650 \\
\hline H3:CO-> BDA & 0.178 & 0.092 & 1.915 & 0.056 \\
\hline H4: TSC->BDA & 0.240 & 0.073 & $3.333^{* *}$ & 0.001 \\
\hline H5:RA->TSC->BDA & 0.040 & 0.034 & 1.203 & 0.229 \\
\hline H6:CO->TSC->BDA & 0.079 & 0.038 & $2.086^{*}$ & 0.038 \\
\hline H7:CX->TSC->BDA & 0.057 & 0.023 & $2.491^{*}$ & 0.013 \\
\hline
\end{tabular}

Figure 5 Structural model's path analysis

The Coefficients of Determination $\left(\mathrm{R}^{2}\right)$ are 0.710 and 0.363 respectively for BDA adoption and technological resource competency. [22] suggested that the values 0.67 and 0.33 of $\mathrm{R}^{2}$ should be viewed as substantial and moderate [22]. Thus, the $\mathrm{R}^{2}$ values of all endogenous constructs were found to be between substantial to moderate, since they were higher than 0.33 . The effect size $\left(\mathrm{f}^{2}\right)$ is based on [22] guidelines. The $\mathrm{f}^{2}$ effect size of $0.02,0.15$, and 0.35 can be used for low, medium, and high effects of the independent latent variables. The complexity has been found to have its low impact on BDA adoption (i.e., $\mathrm{f}^{2}=0.002$ ). However, relative advantage $\left(f^{2}=0.429\right)$, compatibility $\left(f^{2}=0.041\right)$ and technological resource competency $\left(\mathrm{f}^{2}=0.131\right)$ has been found to have high impacts on BDA adoption.

\section{DISCUSSION}

\section{A. Discussion}

Relative advantage from the technological factors has a positive influence on BDA adoption which are consistent with previous literature [22]. However, the complexity and compatibility from technological factors in this study do not have any significant impact on BDA adoption among the manufacturing SMEs in Malaysia. Based on the previous study, owners might find difficult to adopt for lower level employees in their organizations [23]. The adoption of BDA could be influenced by prior experience with other IT systems whereas BDA is perceived as compatible with their current system. Meanwhile, technological resource 
competency was found to have a positive influence on BDA adoption among the companies surveyed. This indicates a consistency with the previous research [24]. Interestingly, this study discovered that technological resource competency significantly mediates between the complexity and BDA adoption among the Malaysian manufacturing SMEs. Similarly, technological resource competency significantly mediates between the compatibility and BDA adoption. However, technological resource competency did not mediate between relative advantage and BDA adoption among the companies. The purpose of this study was to determine the mediating role of technological resource competency between technological factors and BDA adoption among the Malaysian manufacturing SMEs. The empirical result of this research has provided some valuable observations that can add certain values to the current BDA adoption literature. The study also tested the mediating effect of technological resource competency between technology factors and the BDA adoption. There has also been a positive relationship between technological resource competency and BDA adoption. This positive finding is consistent with that of previous studies [11].

\section{B. Theoretical and practical implications}

This study has enriched research literature on the information systems and the adoption of technology. The model of this study provides a new perspective which allows the use of BDA to determine the impact of technological resource competency among Malaysian SMEs. The practical significance of this research provides a variety of contributions and benefits to both academicians and business practitioners. The finding of this study can be used to support the SMEs in manufacturing sector in Malaysia to sustain their business.

\section{CONCLUSION}

This study model is firmly grounded in theory and we have tested it using appropriate survey method and results. There are some limitations of this study which may impact the findings generalizations. This study focused mainly on Malaysian manufacturing SMEs. Consequently, the finding refers only specifically to the Malaysian context and might not be relevant to a heterogeneous context. Future research may examine the results of manufacturing SMEs that adopted BDA in the contexts of different country and conduct a cross-cultural based analysis of the outcomes.

SMEs themselves do need to participate in cultural change, if they are to harness the potential of BDA especially during this pandemic covid-19 crisis. It allows them to explore data handling techniques and approaches beyond their small structures and to be prepared to use BDA effectively in their decision-making processes. They need to be able to dive in and discover the growing ocean of information that awaits them out there. The impacts of COVID-19 on the global economy, other than the support from authorities and government that adopted BDA, will support the SMEs better in decision making process.

\section{REFERENCES}

[1] M. Craven, M. Mysore, S. Singhal, S. Smit, and M. Wilson, "COVID-19: Briefing note, March 30, 2020," no. March, 2020.

[2] TheStar, "WHO says ' aggressive ' action needed in South-East Asia to stop Covid-19," pp. 18-19, 18-Mar2020.

[3] SMEmagazineasia, "A third of SMEs only have enough cashflow for March expenses," p. 2020, Mar2020 .

[4] S. Sun, C. G. Cegielski, L. Jia, and D. J. Hall, "Understanding The Factors Affecting The Organizational Adoption Of Big Data," Journal of Computer Information System., vol. 58, no. 3, pp. 193203, 2016.

[5] C. Raju, "Econ 4.0: How Big Is Big Data?," The Edge Markets, 2018. [Online]. Available: http://www.theedgemarkets.com/article/econ-40-howbig-big-data. [Accessed: 10-Nov-2018].

[6] K. P. Agrawal, "Investigating The Determinants Of Big Data Analytics (BDA) Adoption In Emerging Economies," Academy of Management Proceedings., 2016.

[7] H. U. Khan and V. F. Brock, "Are enterprises ready for big data analytics? A survey-based approach," International Journal of Business Information System., vol. 25, no. 2, p. 256, 2017.

[8] S. Gupta, S. C. Misra, A. Singh, V. Kumar, and U. Kumar, "Identification Of Challenges And Their Ranking In The Implementation Of Cloud ERP," International Journal of Quality \& Reliability Management., vol. 34, no. 7, pp. 1056-1072, 2017.

[9] S. Verma and S. S. Bhattacharyya, "Perceived strategic value-based adoption of Big Data Analytics in emerging economy: A qualitative approach for Indian firms," Journal Enterprise Information Management., 2017.

[10] E. Yadegaridehkordi et al., "The impact of big data on firm performance in hotel industry," Electronic Commerce Research and Application, vol. 40, p. 100921, 2019.

[11] Y. Lai, H. Sun, and J. Ren, "Understanding The Determinants Of Big Data Analytics (BDA) Adoption In Logistics And Supply Chain Management: An Empirical Investigation," International Journal of 
Logistics Management, 2018.

[12] E. M. Rogers, Diffusion Of Innovations (3th ed.). 1983.

[13] G. C. Moore and I. Benbasat, "Development Of An Instrument To Measure The Perceptions Of Adopting An Information Technology Innovation," Information System Research, 1991.

[14] P. F. Hsu, S. Ray, and Y. Y. Li-Hsieh, "Examining Cloud Computing Adoption Intention, Pricing Mechanism, And Deployment Model," International Journal of Information Management., 2014.

[15] M. Amini and A. Bakri, "Cloud Computing Adoption By SMEs In The Malaysia: A MultiPerspective Framework Based On DOI Theory And TOE Framework," Journal of Information Technology Information System Research., 2015.

[16] T. Oliveira, M. Thomas, and M. Espadanal, "Assessing The Determinants Of Cloud Computing Adoption: An Analysis Of The Manufacturing And Services Sectors," Information and Management, 2014.

[17] M. C. Tsai, W. Lee, and H. C. Wu, "Determinants Of RFID Adoption Intention: Evidence From Taiwanese Retail Chains," Information and Management, 2010.

[18] R. G. Fichman, "Real options and IT platform adoption: Implications for theory and practice," Information Systems Research. 2004.

[19] A. Fernández-Mesa, J. L. Ferreras-Méndez, J. Alegre, and R. Chiva, "IT competency and the commercial success of innovation," Industrial Management \& Data Systems., vol. 114, no. 4, pp. 550$567,2014$.

[20] J. F. Hair, M. Sarstedt, L. Hopkins, and V. G. Kuppelwieser, "Partial Least Squares Structural Equation Modeling (PLS-SEM)," European Business Review., 2014.

[21] U. Sekaran and R. Bougie, Research Method Of Business: A Skill-Building Approach 7th Edition, 7th ed. John Wiley \& Sons Ltd, 2016.

[22] J. Henseler, C. M. Ringle, and M. Sarstedt, "A new criterion for assessing discriminant validity in variancebased structural equation modeling," Journal of Academy of. Marketing Science, 2014.

[23] Y. W. Chang, P. Y. Hsu, and Z. Y. Wu, "Exploring managers' intention to use business intelligence: The role of motivations," Behaviour \& Information Technology., vol. 34, no. 3, pp. 273-285, 2015.

[24] Lin and Lin, "Determinants Of E-Business Diffusion: A Test Of The Technology Diffusion Perspective," Technovation, 2008. 